\section{Behavioural neurobiology handbook}

Handbook of Behavioral Neurobiology. Vol.2: Neurophsychology. Pp.566. Edited by M.S. Gazzaniga. (Plenum: New York, 1979.) $£ 35$.

THE general public expect from academic psychologists useful, and preferably unexpected and striking, insights into the human condition. They are interested in the psychology of conscious experience rather than in the minutiae of behaviour and performance usually discussed in academic lecture theatres. It is arguable that while they remain concerned only with human performance academic psychologists can seldom be interesting and never surprising. At best they can clarify the precise nature of limitations of which we have all been aware all our lives, and they make their greatest contribution only by suggesting models for central nervous system function which explain why we have these particular limitations and not others.

In contrast neuropsychologists, who study changes in function after brain damage or central nervous system disease, have far more surprising and vivid stories to tell. Their recent discoveries concern the very texture of daily experience and sometimes offer scary glimpses into the darkness within. Their work raises questions about ourselves and our experience which could hardly have occurred to us in any other way. Until Weiskrantz's recent demonstrations it would have appeared merely a far-fetched philosophical exercise, based on an elementary semantic misconception, to enquire whether any alert and articulate human being could, deliberately on request, make accurate discriminations between patterns which he cannot consciously report seeing. It is also hardly likely that we should have asked, as Le Doux, Wilson and Gazzaniga do in this book, not only whether the two hemispheres of the brain have different and independent functions but also whether, when separated surgically, they may have some degree of independent conscious experience while they share, but independently interpret in different ways, a commonly experienced shift in emotional tone controlled by lower brain centres communicating with both independently.

This second volume of the 'Handbook of Behavioral Neurobiology', edited by Gazzaniga, provokes many such startling questions. It also illustrates many of the conceptual and practical difficulties which beset this fascinating field of new knowledge about ourselves.
The title Handbook raises expectations of a detailed comprehensive reference work. Few of the contributors seem willing to attempt this useful task. Exceptions are the chapter on aphasias by Hecaen, on the frontal lobes by Jonander and Gazzaniga, on thalamic mechanisms in language by Brown, and a useful chapter on long term consequences of central lesions by Newcombe and Ratcliff.

Only a concise chapter on assessment of cognitive deficits in brain-injured patients by Goodglass and Kaplan literally meets the promise of the book's title by providing a handy guide to a complex applied literature for novice practitioners. This chapter, inadvertently, highlights a crucial difficulty currently obstructing progress in neurophysiology. Most tests of function currently used by neurophysiologists and neurosurgeons are crude, pragmatic survivals from wards and consulting rooms fifty or a hundred years ago. They have survived because they are rapidly administered indices which have been found, by experience, to very roughly categorise particular kinds of deficit when and if they are supplemented by the (often brilliant) intuitions of clinicians who, ritualistically, still administer them. A human experimental psychologist, accustomed to constructing models for normal performance at similar tasks, is at once struck by the fact that these particular tests involve such a complex muddle of interacting performance indices that it is quite impossible to say what are the precise functional deficits in performance any of them can demonstrate. However well they may serve as ad hoc diagnostic tools (not too well, reading between the lines of Goodglass and Kaplan's lucid chapter) they as yet give us little insight into the fascinating changes in function which actually accompany particular brain lesions.

The obvious solution is for human, experimental psychologist, knowledgeable about specific indices of performance, to interest themselves in the problem of defining precisely how performance changes when brain lesions occur. Morris Moscovitch's chapter 17 ("Information Processing and the Cerebral Hemispheres') is the nearest attempt to this desirable end. As we see from the bulk of this useful book even crude and conceptually muddled tests of residual function do work in practical diagnosis. The crucial question is why they work, when they work (that is precisely what are the deficits which each of them actually exposes), and whether better, more clearly understood and more efficient diagnostic procedures cannot be developed from the considerable expertise built up by human experimental psychologists. From this point of view Moscovitch's chapter is disappointing. He describes only his own work. He is not concerned with questions of diagnosis but with the relationship of abstract models of human information processing to differences in hemisphere function. This would be interesting if the experimental techniques he uses gave the results which he supposes that they do. In particular the results illustrated in Fig. 1b and Fig. 2 on pages 386-388 and Fig. Sa and $b$ on page 389 may have a number of different interpretations other then those which he places upon them.

For me this is a very exciting book indeed. If the excitement is flawed by impatience I am sorry. But the limitations to further progress are very distressing to anyone who avidly reads chapters $1-4,7$, $9-12,14,15$ and most particularly 17 for the ideas. This is a book which is a key to our current conceptualisations of what we are, and to how the thin bright film of our experience covers the complex darkness within us, out of range of our introspection but perhaps within the grasp of clever and accurate experiments. The lack of experiments is galling, but I would wish the pleasure I have had reading this book to be as widely shared as possible by other scientists of many different educations and fields.

Patrick Rabbitt

Patrick Rabbitt is Lecturer in Experimental Psychology at the University of Oxford, UK.

\section{Plenum Publishing} Corporation

congratulates its author

\section{HERBERT C. BROWN}

recipient of the Nobel prize

for outstanding contributions to chemistry.

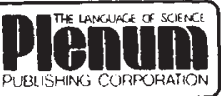

227 West 17 th Street New York, N.Y. 10011

In United Kingdom: Black Arrow House 2 Chandos Road

London NW10 6NR, England 